\title{
Knowledge, Attitudes, and Practices of Pills Splitting in Malaysia: A Cross-Sectional Study
}

\author{
Ahmed Ibrahim Nouri ${ }^{1, *}$, Maha Aldraimly ${ }^{2}$, Nahid Ahmad Lamfon ${ }^{3}$, Nourah Awdah Naytoul AlEnazi ${ }^{2}$, Nawaf Talal Alenazi ${ }^{4}$, \\ Manahel Mohammed Alshair ${ }^{2}$, Mohamed Ahmed ${ }^{5}$ \\ 'School of Pharmaceutical Sciences, Universiti Sains Malaysia, Penang, MALAYSIA. \\ 2Department of Pharmacy, National Gaurd Hospital, Riyadh, SAUDI ARABIA. \\ ${ }^{3}$ College of Medicine, King Saudi University for Health and Science, Riyadh, SAUDI ARABIA. \\ ${ }^{4}$ College of Medicine, Alfaisal University, Riyadh, SAUDI ARABIA. \\ ${ }^{5}$ Faculty of Medicine, Paris-Saclay University, Paris, FRANCE.
}

\begin{abstract}
Background: Tablet-splitting is a common practice in all sectors of healthcare. However, there are certain types of tablets that are not suitable to be split. Reasons to practice tablet splitting are improving dose flexibility, saving cost, and easing swallowing action of the tablets. The study aims to examine and describe the knowledge and practices of tablet splitting, identify the techniques applied by the patients for tablet splitting, and analyze the reasons behind this practice. Methods: This study was conducted as a cross-sectional study using convenient sampling. In total, 390 questionnaires were filled by the respondents throughout the areas in Penang Island within two and half months. Results: About $50 \%$ of the respondents have taken a tablet after splitting it and they were aware of the consequences of inaccurate tablet splitting. Concerning attitudes and practices of the general public towards tablet splitting, most of the respondents $(40.26 \%)$ split their tablets by hand, followed by knife $(28.72 \%)$, tablet-splitter
\end{abstract}

$(22.05 \%)$, teeth $(10.77 \%)$, and dissolve the whole tablet in the water and drink it (3.08\%). Conclusion: Tablet splitting has a major role in dosage adjustment and should be limited to the specific clinical situation. If tablet splitting is still necessary, patient counseling is recommended, and pharmacies should deliver the appropriate tools or pharmacist split tablets for the patients and repackages them.

Key words: Pharmacy practice, Tablet splitting, Attitude, Knowledge, Clinical perspective.

\section{Correspondence}

Dr. Ahmed Ibrahim Nouri,

Discipline of Clinical Pharmacy, Universiti Sains Malaysia, Penang, MALAYSIA. Email id: ahmad090@hotmail.com

DOI: 10.5530/jyp.2021.13.99

\section{INTRODUCTION}

Oral administration is one of the most preferred routes of drug administration where a substance is taken through the mouth. Being more convenient, cost-effective, and easy to administer leads to a high level of patient compliance. Many medications are taken orally because they are intended to have a systematic effect, reaching different parts of the body via the bloodstream. Pills are composed of a mixture of active substances and excipients, usually in powder form, pressed or compacted from a powder into a solid form. The excipients can include diluents, binders or granulating agents, glidants (flow aids), and lubricants to ensure the efficiency of the tablets. This will avoid the tablets from disintegrating or promote tablet break-up in the digestive tract. A polymer coating is often applied to make the tablet smoother and easier to swallow, to control the release rate of the active ingredient, to make it more resistant to the environment (extending its shelf life), or to enhance the tablet>s appearance. ${ }^{1}$ About two-thirds of all prescriptions are dispensed as solid dosage forms, and half of these are compressed tablets. ${ }^{2}$ Medicinal tablets were originally made in the shape of a disk of whatever color their components determined but are now made in many shapes and colors to help distinguish different medicines. Tablets are often stamped with symbols, letters, and numbers, which enable them to be identified. Sizes of tablets to be swallowed range from a few millimeters to about a centimeter. Thus, the oral drug delivery system is the most viable option and is always favored. However, if the oral route is not immediately viable, pharmaceutical companies will often invest resources in making it feasible, rather than plumping for an alternative delivery method.
Tablet of splitting tends to be performed by pharmacists, nurses, patients, or their caregivers. It is commonly applied in clinical practice to overcome drug amount restrictions. Among the reasons to split tablets by patients is to obtain a lower dose of the active ingredient of the tablets available that are in a larger dose than needed. Also, patients tend often to divide tablets to save costs. ${ }^{3,4}$ Tablet splitting would be able to have an economic incentive benefitting both the individual patient and the healthcare providers. The estimation of cost-saving for these practices from innovative pharmaceutical companies is as high as $40-50 \% .^{5}$ Moreover, a more dominant motive to split tablets is due to swallowing difficulties among elders and children. Santen et al. proposed that pediatric and geriatric patients usually split their tablets to acquire the appropriate dosage requirements for an individual as the suitable doses are often not available in the market. ${ }^{6}$

However, the public tends to think that all tablets can be split, and even capsules can be opened. There are certain types of tablets that are not recommended to be split. For instance, enteric-coated tablets and film coating tablets. Various concerns need to be taken into consideration before splitting a tablet even it has a score line. For example, disproportionate drug content and drug stability of divided tablets. These can influence the functioning of the drugs' absorption and distribution in the body. In addition, certain drugs like narrow therapeutic index drugs need to be handled with extra caution as any sub-therapeutic or extra-therapeutic dose can bring harmful consequences. ${ }^{7}$ Most of the leaflet provides information on the tablet but it does not provide any 
information about whether the tablet is suitable to be split. Therefore, patients will not know the divisibility of the tablet unless they ask health professionals more regarding that topic. ${ }^{8}$

In Malaysia, there is no tablet-splitting guideline implemented by the government for health professionals. Under this circumstance, little is known about the tablet splitting practice in Malaysia. According to Hassali et al. the overall patients' acceptance rate for tablet splitting recommendation was $82.1 \%$. The majority of patients accept the recommendations involved anti-hyperlipidemic agents (83.3\%) and cardiovascular drugs (75.0\%). ${ }^{9}$ Thus, to encourage patients in Malaysia to practice tablet splitting, a tablet-splitting guideline should be developed to avoid inappropriate splitting done by the patients.

Patients usually practice dividing tables with a scoreline by hand. Tablets without the scoreline may require the use of a razor, scissors, or knife. Similarly, capsules are split by emptying the powder and dividing it into equal portions. Nevertheless, the patients who practice tablet splitting should be cautious to ensure that they are having the dose correctly. With the variated practices and behavior by the community for splitting tablets, the current research aims to examine and describe the knowledge and practices of tablet splitting, identify the techniques applied by the patients for tablet splitting, and analyze the reasons behind these practices.

\section{METHODS}

This is a cross-sectional survey study. A validated questionnaire was distributed among the public visiting community pharmacies and clinics in Penang Island, Malaysia. A convenience sampling was performed to survey the participants of this study. The sample size required for the survey was calculated using Raosoft with a 95\% confidence level, 5\% margin of error, and $50 \%$ of response distribution. The minimum recommended sample size of the survey was 377 participants, the research team collected 390 questionnaires. Participants of age above 18 years of various ethnicities of Penang (Malay, Indian, Chinese, and others) were included.

Literature was reviewed on the expected knowledge, attitude, and practice of the public with splitting of tablets and framed into a questionnaire. The developed questionnaire was reviewed by pharmaceutical care experts in academia for face validity. It was also assessed for content validity in terms of content, scope, depth, and appropriateness of each item of the questionnaire.

Initially, a total number of 86 questions was developed by the research team on tablet splitting practices. Next, the questionnaire was reviewed, and items were narrowed down to 16 questions either because questions were repeated or irrelevant or some were merged. The questionnaire consisted of three sections. The first was about demographic data which contained 8 questions regarding the demographic background of the respondent including gender, age, ethnicity, marital status, education qualification, and income. The second section was about awareness and knowledge of the public towards tablet splitting which consists of 10 questions (yes or no questions). Lastly, the third section is about the attitude and practices of the public toward tablet splitting which contained 6 questions (multiple choice questions).

The research team visited clinics and community pharmacies at various places in Penang Island, Malaysia. Each respondent was required to read the consent form and brief of the research then sign them before start answering the questionnaire. Statistical Package for Social Sciences (SPSS) was used to analyze the data.

\section{RESULTS}

\section{Socio-Demographic characteristics of participants}

A total of 390 questionnaires were distributed to the public at community pharmacies and clinics in Penang, Malaysia. Table 1 summarizes the socio-demographic characteristics of respondents.

Table 1: Socio-Demographic Characteristics ( $N=390)$

\begin{tabular}{|c|c|c|}
\hline Variable & $\mathbf{N}$ & (\%) \\
\hline \multicolumn{3}{|c|}{ Age (years) } \\
\hline$<20$ & 20 & $(5.13)$ \\
\hline $20-29$ & 184 & $(47.18)$ \\
\hline $30-39$ & 85 & $(21.79)$ \\
\hline $40-49$ & 54 & $(13.85)$ \\
\hline $50-59$ & 33 & $(8.46)$ \\
\hline $60-69$ & 11 & $(2.82)$ \\
\hline$>70$ & 3 & $(0.77)$ \\
\hline \multicolumn{3}{|c|}{ Gender } \\
\hline Male & 140 & $(35.90)$ \\
\hline Female & 250 & $(64.10)$ \\
\hline \multicolumn{3}{|c|}{ Ethnicity } \\
\hline Malay & 186 & $(47.69)$ \\
\hline Chinese & 123 & $(31.54)$ \\
\hline Indian & 60 & $(15.38)$ \\
\hline Arab & 16 & $(4.10)$ \\
\hline Others (Kadazan-Dusun, Caucasian) & 5 & $(1.28)$ \\
\hline \multicolumn{3}{|c|}{ Marital Status } \\
\hline Single-never married & 218 & $(55.90)$ \\
\hline Married & 159 & $(40.77)$ \\
\hline Separated or divorced & 8 & $(2.05)$ \\
\hline Widowed & 5 & $(1.28)$ \\
\hline \multicolumn{3}{|c|}{ Educational Level } \\
\hline College/University & 314 & $(80.51)$ \\
\hline Secondary School & 64 & $(16.41)$ \\
\hline Primary School & 5 & $(1.28)$ \\
\hline No formal education & 7 & $(1.79)$ \\
\hline \multicolumn{3}{|c|}{ Occupation } \\
\hline Private/self-employed & 184 & $(47.18)$ \\
\hline Student & 116 & $(29.74)$ \\
\hline Government & 63 & $(16.15)$ \\
\hline Unemployed & 18 & $(4.62)$ \\
\hline Retired & 9 & $(2.31)$ \\
\hline \multicolumn{3}{|c|}{ Monthly Income ${ }^{\star}$} \\
\hline RM1000 or below & 121 & $(31.03)$ \\
\hline RM1001-RM1500 & 46 & $(11.79)$ \\
\hline RM1501-RM2000 & 43 & $(11.03)$ \\
\hline RM2001-RM2500 & 51 & $(13.08)$ \\
\hline Above RM2500 & 129 & $(33.08)$ \\
\hline
\end{tabular}

${ }^{*} \mathrm{RM} 1=$ USD 0.2390 


\section{Awareness and Knowledge of General Public towards Tablet Splitting}

The general knowledge of respondents towards tablet splitting practices is summarized in Table 2. A high number of respondents, 261 (66.92\%) have taken a split tablet previously and more than half of them (56.41\%) thought that splitting tablets was not suitable for any type of tablet. Nearly half of them (51.79\%) agreed that splitting can be carried out for any medication and with any indication. Almost half of the respondents believed that dividing the tablet into half will not result in equal doses (54.11\%). Almost two-third assumed that a tablet with a scoreline is suitable for splitting (69.49\%). More than half of the patients $(229,58.72 \%)$ knew that tablets with special coating have a specific function and splitting the tablets will cause a negative impact. Regarding capsules, 235 patients $(60.26 \%)$ thought that it was inappropriate to open and consume the content inside.

\section{Attitude and Practices of General Public towards Tablet Splitting}

This section was given to assess the attitude and practices of the general public towards tablet splitting as shown in Table 3. This showed that the respondents were unaware of the correct method used. However, actual dosages of hand-split tablets may deviate by more than $20 \%$ and it may cause differences in the content of the two halves which may affect the cure of the disease especially if the dose is critical in disease treatment. When splitting cannot be avoided, for example when the prescribed dose is not commercially available, the recommended method was to use an accurate splitting device.

Table 2: Awareness and Knowledge of General Public towards Tablet Splitting ( $N=390)$.

\begin{tabular}{|c|c|c|c|}
\hline & Question & Yes & No \\
\hline 1. & Have you ever taken a tablet/pill after splitting it? & $\begin{array}{c}261 \\
(66.92 \%)\end{array}$ & $\begin{array}{c}129 \\
(33.08 \%)\end{array}$ \\
\hline 2. & $\begin{array}{l}\text { Do you think any type of tablets/pills can be } \\
\text { split? }\end{array}$ & $\begin{array}{c}170 \\
(43.59 \%)\end{array}$ & $\begin{array}{c}220 \\
(56.41 \%)\end{array}$ \\
\hline 3. & $\begin{array}{l}\text { Do you think any medication for any indication } \\
\text { could be split? }\end{array}$ & $\begin{array}{c}202 \\
(51.79 \%)\end{array}$ & $\begin{array}{c}188 \\
(48.21 \%)\end{array}$ \\
\hline 4. & $\begin{array}{l}\text { Do you think dividing the tablet will give equal } \\
\text { doses in each half? }\end{array}$ & $\begin{array}{c}179 \\
(45.89 \%)\end{array}$ & $\begin{array}{c}211 \\
(54.11 \%)\end{array}$ \\
\hline 5. & $\begin{array}{l}\text { When you see a scored tablet (tablet with a line } \\
\text { on the middle) then this tablet can be split? }\end{array}$ & $\begin{array}{c}271 \\
(69.49 \%)\end{array}$ & $\begin{array}{c}119 \\
(30.51 \%)\end{array}$ \\
\hline 6. & $\begin{array}{l}\text { You think tablets can ONLY be split when you } \\
\text { have a prescription with a dosage where tablets } \\
\text { must be split. }\end{array}$ & $\begin{array}{c}280 \\
(71.79 \%)\end{array}$ & $\begin{array}{c}110 \\
(28.21 \%)\end{array}$ \\
\hline 7. & $\begin{array}{l}\text { Do you think there is an actual reason why some } \\
\text { doses are not available, and patients do have to } \\
\text { split? }\end{array}$ & $\begin{array}{c}277 \\
(71.03 \%)\end{array}$ & $\begin{array}{c}113 \\
(28.97 \%)\end{array}$ \\
\hline 8. & $\begin{array}{l}\text { Do you know that some tablets have a special } \\
\text { coating designed to pursue a specific function } \\
\text { and splitting the tablet will affect it negatively? }\end{array}$ & $\begin{array}{c}229 \\
(58.72 \%)\end{array}$ & $\begin{array}{c}161 \\
(41.28 \%)\end{array}$ \\
\hline & $\begin{array}{l}\text { Do you think that inaccurate tablet splitting } \\
\text { can lead to a negative impact on your health } \\
\text { outcome? }\end{array}$ & $\begin{array}{c}254 \\
(65.13 \%)\end{array}$ & $\begin{array}{c}136 \\
(34.87 \%)\end{array}$ \\
\hline 10. & $\begin{array}{l}\text { Do you think it is ok for capsules to be opened } \\
\text { and consume the powder/granules inside? }\end{array}$ & $\begin{array}{c}155 \\
(39.74 \%)\end{array}$ & $\begin{array}{c}235 \\
(60.26 \%)\end{array}$ \\
\hline
\end{tabular}

Table 3: Attitude and Practices of General Public towards Tablet Splitting.

\begin{tabular}{|c|c|c|}
\hline Question & Total & Percentage (\%) \\
\hline \multicolumn{3}{|l|}{ 1. How do you split tablets? } \\
\hline No tool (Hand) & 157 & 40.26 \\
\hline No tool (Teeth and bite) & 42 & 10.77 \\
\hline Tool (Tablet-splitter) & 86 & 22.05 \\
\hline Tool (Knife) & 112 & 28.72 \\
\hline $\begin{array}{l}\text { Dissolve the whole tablet in water and drink } \\
\text { half of it. }\end{array}$ & 12 & 3.08 \\
\hline Other & 7 & 1.79 \\
\hline \multicolumn{3}{|l|}{$\begin{array}{l}\text { 2. Have you ever encountered any difficulty/ } \\
\text { confusion during tablet splitting? }\end{array}$} \\
\hline Uneven halves & 160 & 41.78 \\
\hline Lazy to split & 68 & 19.53 \\
\hline A tablet without a scoreline & 122 & 31.85 \\
\hline Tablet too small to split. & 172 & 44.91 \\
\hline \multicolumn{3}{|l|}{$\begin{array}{l}\text { 3. Do you change the storage conditions of the } \\
\text { remaining tablets after splitting? }\end{array}$} \\
\hline $\begin{array}{l}\text { Yes, I keep it on a cover and keep it in the } \\
\text { fridge. }\end{array}$ & 96 & 25.07 \\
\hline $\begin{array}{l}\text { Yes, I keep it in a cover and keep it in the } \\
\text { container }\end{array}$ & 129 & 33.68 \\
\hline No, I just put it in the container or sachet. & 131 & 34.20 \\
\hline No, I discard the remaining. & 31 & 8.09 \\
\hline \multicolumn{3}{|l|}{$\begin{array}{l}\text { When parts of the divided tablets did not } \\
\text { result in equal parts you ... }\end{array}$} \\
\hline Discard it and split a new one. & 127 & 33.16 \\
\hline Take the tablets after division regardless & 256 & 66.84 \\
\hline \multicolumn{3}{|l|}{$\begin{array}{l}\text { Have you ever forgotten to split a tablet and } \\
\text { took the whole tablet instead? }\end{array}$} \\
\hline Yes & 184 & 48.04 \\
\hline No & 199 & 51.96 \\
\hline \multicolumn{3}{|l|}{$\begin{array}{l}\text { If you don't know about a tablet whether can } \\
\text { be split or not, what do you do? }\end{array}$} \\
\hline I ask a healthcare professional. & 158 & 41.15 \\
\hline I decide not to split and take it whole. & 107 & 27.86 \\
\hline I read the leaflet. & 97 & 25.26 \\
\hline I split either way. & 29 & 7.55 \\
\hline Google & 2 & 0.52 \\
\hline
\end{tabular}

\section{DISCUSSION}

A pill or capsule may be difficult for certain people to swallow. Although certain drugs can be safely chewed, crushed, or sliced (tablet splitting) to help with administration, there is a growing list of pharmaceuticals that are considered harmful to manipulate in this way due to their formulations or pharmacokinetic features. These drugs are varied and include analgesics, cardiovascular medicines, non-steroidal anti-inflammatory drugs, antiepileptic's, and antibiotics among other drug groups. However, commonly used drugs such as phenytoin, isosorbide, nifedipine, and verapamil should not be chewed or crushed.

In pharmacy practice, tablet splitting is a typical phenomenon. Tablet splitting may be recommended by healthcare practitioners for a variety 
of reasons, including cost savings, dosage adjustments, and overcoming swallowing issues. This method, however, is not without danger; it can result in erroneous dosing and the splitting of pharmaceuticals that should not be divided, such as controlled-release drugs. ${ }^{10-12}$

The current research was conducted in Malaysia to delve into the knowledge, attitudes, and practices of patients regarding tablet splitting. Among 390 patients who were surveyed, most of them believe that not all types of tablets can be split. This showed that the public in Malaysia was quite aware of the existence of different types of tablets available in the pharmacies.

The awareness of the public in Penang, Malaysia can be considered satisfactory unlike a study conducted in India that found the respondents had poor awareness regarding the danger of pill-splitting. ${ }^{13}$

The most common type of tablet that they know splitting is acceptable was those tablets with a scoreline. Unscored tablets such as metformin (Diaformin 850), unusually thick or oddly shaped tablets such as alendronate $40 \mathrm{mg}$ (Fosamax $40 \mathrm{mg}$ ), film-coated tablets such as nifedipine (Nifecard), enteric-coated tablets such as pantoprazole (Somac) as well as extended-release tablets such as potassium chloride (KSR, Slow KSR, Span K) were types of tablets that should not be split. ${ }^{14}$ Almost half of the respondents thought that any medication could be split. This showed that almost half of the respondents were not aware of the formulation of tablets. For medications with a narrow therapeutictoxic range such as warfarin or digoxin, large dose deviation or weight loss could lead to severe clinical consequences. ${ }^{4}$ The public should always consult health care professionals if they have any doubt regarding whether the tablet was suitable to be split. This is because inappropriate splitting might lead to serious impacts which may bring negative effects to body health.

$54.11 \%$ of respondents agreed that tablet splitting reduced the dose of the drug but would not give equal doses in each half. As approved by the Food and Drug Administration (FDA), splitting scored tablets can be considered safe and efficacious. However, studies related to dose content uniformity showed that the half tablet weights 5 of divided scored tablets did not pass the test. In addition, almost $25 \%$ of halved tablets were found not within the United States Pharmacopeia (USP) specifications when a study about the drug content by chemical assay was carried out. Physical characteristics like scoring and shape were not the determining factors to predict whether that product would pass the uniformity test. ${ }^{15}$ The inaccuracy degree might be linked with tablet size, shape, and type of scoring on the surface of the tablet. ${ }^{16}$ Nevertheless, the public was encouraged to use a tablet splitter to carry out splitting instead of using hands as a table splitter could guarantee a more equal half than that of using a hand.

Most patients supposed that a scored tablet is appropriate to be split. Suitability to be divided is the main consideration by the manufacturer to manufacture tablets with a scoreline. Most of the tablets were produced this way. Nevertheless, not all scored tablets were appropriate to be split, and this should be considered when the approval to split the tablet was made. Tablets with scored on one side only such as alprazolam (Kalma), benztropine (Cogentin), selegiline (Eldepryl), and clozapine (Clozaril) were difficult to achieve accurate tablet splitting (Marriott and Nation, 2002). Some tablets may not easily break into two equal pieces even though the scoreline was present. ${ }^{17}$

The majority of respondents (71.79\%) agreed that splitting could be done only when a prescription order states to do so given by a health care professional. Misinterpretation of the prescription or label instructions by the pharmacist or patient may cause a risk of errors in tablet splitting. However, tablet splitting will not compromise patient adherence and satisfaction or clinical outcomes negatively if proper counseling and prudent implementation were given by health care professionals. ${ }^{15}$ Thus, patients must not make their own decision in splitting tablets unless he is aware of the consequences as a different dosage of medication, even if varied in a small amount, might result in severe negative health outcomes.

From the study, the majority of respondents believed that there was an actual reason for the unavailability of some doses. There were several obstacles to manufacturing low-dose drugs. Mixing and formulation of low-dose drugs involved complicated and sophisticated procedures such as segregation, content uniformity, and physical stability. ${ }^{18}$ Physical stability was very important because it will determine the condition of the tablet under the influence of environmental factors, temperature, humidity, and light. Hence, the manufacturer decided not to manufacture low-dose drugs due to the difficulty to control the physical stability as well as to save cost on purchasing the specific machine and material required. Micronization process needed to be carried out to produce low-dose drugs to increase the number of particles of drugs in which could be blended with other excipients to increase homogeneity in formulations as well as the final dosage form. ${ }^{18}$

The present study found that $58.72 \%$ of respondents were aware of the specific function of a special coat on certain tablets and splitting the tablet will cause negative effects. The coating played an important role in dissolution rate and absorption characteristics in coated and controlledrelease tablets. Felodipine (Agon SR) and tramadol (Tramal SR) were examples of drugs that their coats cannot be removed. This is because splitting or the removal of the coating will affect their extended-release characteristics. ${ }^{16}$ Hence, the public was advised to take the whole tablet instead whenever splitting is unnecessary to ensure the optimum degradation rate of the drug.

The current research found that $34.87 \%$ of the respondents thought that inaccurate tablet division will not cause any significant impact on clinical outcomes. This data represented the minority group of the public who were not attentive about the importance of doses in the drug. Inaccurate tablet division resulted in little or much dose deviations depended on how the division was carried out. This fluctuation of administered dose might not cause any clinically significant for medications with a wide therapeutic range or long half-lives. Nevertheless, serious consequences might occur with narrow therapeutic-toxic range medications. ${ }^{4}$ For example, Theophylline will cause potential toxicity to occur if the serum concentration exceeds $20 \mathrm{mg} / \mathrm{L}$. This serious toxicity was due to its unsystematic use which eventually results in serious arrhythmias.

In addition, the majority of respondents disagreed with consuming the powder or granules inside by opening the capsules. This showed that most of the patients have had the correct mindset regarding consuming capsules. Opening capsules could alter the rate of absorption of a drug where fatal might happen due to overdose or underdose. When a drug's sustained-release properties were disrupted, overdosing occurred as the active ingredient was no longer released and absorbed. On the other side, when a gastro-resistant layer is destroyed by crushing, underdosing was likely to occur. All these factors contributed to the ineffective treatment given to the patient. Furthermore, the person who did the crushing or opening was exposed to carcinogenic, teratogenic, or fetotoxic drug particles.

Based on the current research, a double percentage of respondents $(40.26 \%)$ split the tablets using a bare hand while only $22.05 \%$ of respondents split the tablet using a tablet-splitter. To avoid dosage deviation, manufacturers can introduce a wider range of tablet doses or liquid formulations. ${ }^{19}$

The current research showed that respondents had encountered difficulty during tablet splitting. There were $41.78 \%$ of them facing the uneven halves of tablets and $44.91 \%$ of them thought that the tablets were too 
small to be split. Some tablets such as digoxin (Lanoxin-PG) and temazepam (Temaze) were too small to split evenly, resulting in the tablets becoming crumble or not the exact dose needed. The inaccurate dose, even a small difference in two halves of a split tablet could put our health at risk. Uneven splitting of a tablet may be clinically significant for drugs with a narrow therapeutic range, such as warfarin or digoxin. ${ }^{19}$ The present study discovered that respondents who kept the remaining tablets in a cover and then kept in a container, and those who just kept in the container, had almost the same percentage which was $33.68 \%$ and $34.20 \%$ respectively. This means that a big chunk of the public does not store the split pill properly. The storage condition of remaining tablets is vital, factors such as heat, humidity, or moisture might affect the pills' efficacy. The stability of medications after splitting is not common knowledge even for healthcare professionals, thus, one must be vigilant to such practices. Many patients, nurses, or pharmacists, split several tablets in advance, the split tablets might get stored in containers that were previously used for the same medication or a different medication. This may yield to numerous troubles such as the label is stating a different drug, the split tablets might be exposed to air and light, which then will cause a possible detrimental effect on the stability.

Furthermore, when parts of divided tablets do not result in equal parts, there were $66.84 \%$ of respondents decided to take the tablets after splitting regardless. This indicated that the awareness of respondents towards the accuracy of tablet splitting is not satisfactory. Uneven halves of tablets would result in weight variation and non-uniformed drug content. These could potentially impact the drug performance and could bring harm to patients, especially for the drugs with narrow therapeutic index, drugs with closely spaced multiple strengths, and drugs with nonlinear pharmacokinetics. ${ }^{20}$

On the other hand, there were almost half of the respondents (51.96\%) stated that they never forgot to split a tablet. However, the rest of them (48.04\%) who forgot to split the tablet decided to take the whole tablet instead. Hence, most patients who bought a higher dose with the intention to split would result in a double dose if they forgot to split the tablets. Taking the double amount of medication with the same active ingredient at a time could increase the chance of negative side effects. For example, taking too much acetaminophen (more than 4,000 mg/24 hr) could harm the liver. ${ }^{21} \mathrm{~A}$ study showed that some patients were taking too much medication because they forgot to split their tablets and two-thirds of the patients received more than the intended dose. ${ }^{22}$

Moreover, almost half $(41.15 \%)$ of the respondents answered that they would ask a healthcare professional when they do not know about a tablet can be split or not. This was then followed by $28.86 \%$ of them who decided not to split and to take it whole. Patients were required to get the actual answer before taking the medication. Indeed, the information will be printed in the 'how supplied' section if the tablet was FDA-approved to be split. If the tablet does not include such information, which indicated that there was no evaluation from the FDA to ensure the two halves of the split tablet were the same in drug content or work the same way in our body as the whole tablet, patients should discuss with a healthcare professional to get the appropriate advice. Patients were encouraged to seek an answer if they were curious whether the tablets could be split or not. It is the healthcare professional's responsibility to monitor the risks associated with the practice of tablet splitting.

\section{CONCLUSION}

Most of the respondents will split the tablets by using their hands. Consequently, this may lead to uneven halves of split tablets, and this is also the main problem encountered by the respondents. The uneven halves of the tablet may result in deviation in dose. Dose deviation when splitting a certain type of tablet is not a common problem. However, this becomes problematic when we are talking about larger dose deviations and drugs with a narrow therapeutic index. In this context, they should have been taught to use the correct method such as tablet splitter to split the tablet. Healthcare professionals and other healthcare authorities play an important role in increasing the knowledge of the general public regarding tablet splitting practice. This can be achieved by distributing pamphlets and brochures to the general public so that the general public is exposed to the knowledge of tablet splitting practices. However, before they make an effort to increase the public's knowledge about the tablet splitting practices, they need to work together to raise the general public's awareness about the negative effects of tablet splitting if it is practiced inappropriately. Once the public has this awareness only, they will start to make effort to prevent the undesirable effect of tablet splitting. Healthcare professionals and other healthcare authorities can also plan and organize a talk or workshop to raise public awareness of the tablet splitting practice.

In short, tablet splitting has a major role in dosage adjustment and should be limited to the specific clinical situation. If tablet splitting is still necessary, patient counseling is recommended, and pharmacies should deliver the appropriate tools or pharmacist split tablets for the patients and repackages them.

\section{Ethical considerations}

Ethical permission to conduct the study was obtained from the school of pharmaceutical sciences ethical committee, USM. Confidentiality of the information obtained from patients was maintained. Informed consent was obtained from each respondent before participation.

\section{ACKNOWLEDGEMENT}

The authors would like to acknowledge the pharmacy students at the school of pharmaceutical sciences in Universiti Sains Malaysia for helping in the distribution of the questionnaire and data collection.

\section{CONFLICT OF INTEREST}

The authors declare that they have no conflict of interest.

\section{REFERENCES}

1. Darii MA, Lalge RM, Marathe SP, Mulay TD, Fatima T, Alshammari A, Lee HK, Repka MA, Narasimha Murthy S. Excipient stability in oral solid dosage forms: a review. AAPS PharmSciTech. 2018;19(1):12-26. doi: 10.1208/s12249-017-0864-4, PMID 28895106.

2. Lau ETL, Steadman KJ, Cichero JAY, Nissen LM. Dosage form modification and oral drug delivery in older people. Adv Drug Deliv Rev. 2018;135:75-84. doi: 10.1016/j.addr.2018.04.012, PMID 29660383.

3. Freeman MK, White W, Iranikhah M. Tablet splitting: a review of the clinical and economic outcomes and patient acceptance. Second of a 2-part series. Part 1 was published in May. Consult Pharm. 2012;27(6):421-30 (Cameron KA. Consult Pharm. Healthy aging: programs that make a difference-part 1. 2012;27(4):239-53. doi: 10.4140/TCP.n.2012.239, PMID 22498985).

4. Verrue C, Mehuys E, Boussery K, Remon JP, Petrovic M. Tablet-splitting: a common yet not so innocent practice. J Adv Nurs. 2011;67(1):26-32. doi: 10.1111/j.1365-2648.2010.05477.x, PMID 21158902.

5. Tahaineh LM, Gharaibeh SF. Tablet splitting and weight uniformity of half-tablets of 4 medications in pharmacy practice. J Pharm Pract. 2012;25(4):471-6. doi: 10.1177/0897190012442716, PMID 22544621.

6. Van Santen E, Barends DM, Frijlink HW. Breaking of scored tablets: a review. Eur J Pharm Biopharm. 2002;53(2):139-45. doi: 10.1016/s0939-6411(01)00228-4, PMID 11879995.

7. Freeman MK, White W, Iranikhah M. Tablet splitting: a review of weight and content uniformity. Consult Pharm. 2012;27(5):341-52. doi: 10.4140/ TCP.n.2012.341, PMID 22591978.

8. Arandy DA, Abu-Hashia MW, Al-Hroub BM, Qatmosh SA, Koni AA, Qeeno BG, Al-Jabi SW, Zyoud SH. Comparative evaluation of drug information leaflets for non-steroidal anti-inflammatory drugs in Palestine: local versus imported products. BMC Health Serv Res. 2019;19(1):892. doi: 10.1186/s12913-0194754-1, PMID 31771571. 
9. Chong $\mathrm{CP}$, Hassali MA, Bahari MB. Evaluation of tablet splitting practices among Malaysian community pharmacists. Malays J Pharm Sci. 2012;1(10):19.

10. Chou CL, Hsu CC, Chou CY, Chen TJ, Chou LF, Chou YC. Tablet splitting of narrow therapeutic index drugs: a nationwide survey in Taiwan. Int J Clin Pharm. 2015;37(6):1235-41. doi: 10.1007/s11096-015-0194-0, PMID 26399507.

11. Dormuth CR, Schneeweiss S, Brookhart AM, Carney G, Bassett K, Adams S, et al. Frequency and predictors of tablet splitting in statin prescriptions: a population-based analysis. Open Med. 2008;2(3):e74.

12. Quinzler R, Gasse C, Schneider A, Kaufmann-Kolle P, Szecsenyi J, Haefeli WE. The frequency of inappropriate tablet splitting in primary care. Eur J Clin Pharmacol. 2006;62(12):1065-73. doi: 10.1007/s00228-006-0202-3, PMID 17024485.

13. Baig SY, Bashir L, Naz E, Naz S, Ghiasuddin M, Siddiqui D, et al. Pill splitting a risky practice. World J Pharm Res. 2016;5(8):118-31.

14. Marriott JL, Nation RL. Splitting tablets. Aust Prescr. 2002;25(6):133-5 + 51. doi: 10.18773/austprescr.2002.131

15. Mosena MS, Van der Merwe E. The appropriateness and risks of tablet splitting: medifile: clinical review. SA Pharm J. 2009;76(7):30-6.

16. Gracia-Vásquez, S. L., González-Barranco, P., Camacho-Mora, I. A., González-
Santiago, O., \& Vázquez-Rodríguez, S. A. Medications that should not be crushed. Medicina Universitaria, 2017;19(75):50-63.

17. McDevitt JT, Gurst AH, Chen Y. Accuracy of tablet splitting. Pharmacotherapy, 1998;18(1):193-7. PMID 9469693.

18. Kukkar V, Anand V, Kataria M, Gera M, Choudhury PK. Mixing and formulation of low dose drugs: underlying problems and solutions. Thai J Pharm Sci. 2008;32(3-4):43-58

19. Habib WA, Alanizi AS, Abdelhamid MM, Alanizi FK. Accuracy of tablet splitting comparison study between hand splitting and tablet cutter. Saudi Pharm J. 2014;22(5):454-9. doi: 10.1016/j.jsps.2013.12.014, PMID 25473334

20. Shah RB, Collier JS, Sayeed VA, Bryant A, Habib MJ, Khan MA. Tablet splitting of a narrow therapeutic index drug: a case with levothyroxine sodium. AAPS PharmSciTech. 2010;11(3):1359-67. doi: 10.1208/s12249-010-9515-8, PMID 20740332.

21. Sheen CL, Dillon JF, Bateman DN, Simpson KJ, Macdonald TM. Paracetamo toxicity: epidemiology, prevention and costs to the health-care system. Qjm. 2002;95(9):609-19. doi: 10.1093/qjmed/95.9.609, PMID 12205339.

22. Grissinger M. Tablet splitting-only if you'half'to. Pharmacol Ther. 2010;35(2):69-70.

Article History: Received: 30-06-2021; Revised: 20-07-2021; Accepted: 21-09-2021.

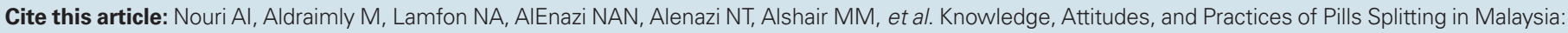
A Cross-Sectional Study. J Young Pharm. 2021;13(4):411-6. 